TI 2013-117/VIII

Tinbergen Institute Discussion Paper

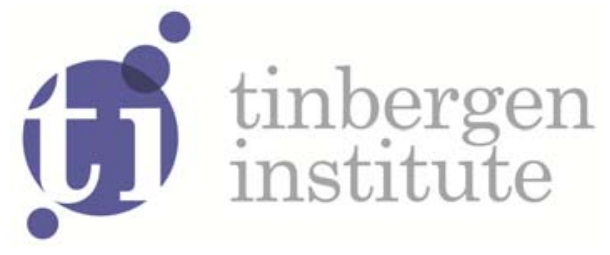

\title{
Tender Auctions with Existing Operators Bidding
}

Vincent A.C. van den Berg

Faculty of Economics and Business Administration, VU University Amsterdam, and Tinbergen Institute. 
Tinbergen Institute is the graduate school and research institute in economics of Erasmus University Rotterdam, the University of Amsterdam and VU University Amsterdam.

More TI discussion papers can be downloaded at http://www.tinbergen.nl

Tinbergen Institute has two locations:

Tinbergen Institute Amsterdam

Gustav Mahlerplein 117

1082 MS Amsterdam

The Netherlands

Tel.: +31(0)205251600

Tinbergen Institute Rotterdam

Burg. Oudlaan 50

3062 PA Rotterdam

The Netherlands

Tel.: +31(0)10 4088900

Fax: $+31(0) 104089031$

Duisenberg school of finance is a collaboration of the Dutch financial sector and universities, with the ambition to support innovative research and offer top quality academic education in core areas of finance.

DSF research papers can be downloaded at: http://www.dsf.nl/

Duisenberg school of finance

Gustav Mahlerplein 117

1082 MS Amsterdam

The Netherlands

Tel.: +31(0)20 5258579 


\title{
Tender auctions with existing operators bidding ${ }^{*}$
}

Version of 14 August 2013

\author{
Vincent A.C. van den Berg \\ v.a.c.vanden.berg@vu.nl \\ Department of Spatial Economics \\ Tinbergen Institute \\ VU University Amsterdam \\ Gustav Mahlerplein 117 \\ De Boelelaan 1105 \\ 1082 MS, Amsterdam \\ $1081 \mathrm{HV}$, Amsterdam \\ The Netherlands
}

The Netherlands

\begin{abstract}
Consider a government tendering a facility, such as an airport or utility, where one bidder owns a competing facility. With a "standard auction", this "existing operator" bids above the auctioned facility's expected profit, as winning means being a monopolist instead of a duopolist. This auction leads to an unregulated outcome which hurts welfare. A consumerprice auction can alleviate this problem. With complementing facilities, the existing operator offers a price below marginal cost and is more likely to win than other bidders; with substitutes, it is less likely to win. Often, the advantaged bidder always wins, eliminating competition for the field.
\end{abstract}

\footnotetext{
*I am grateful for the comments of Harry van der Weijde, Sergej Gubins, Paul Koster, Alex Dimitropoulos, Hugo Silva, Erik Verhoef and Eva Gutiérrez. I would also like to thank the participants of the Eureka seminar (2012), NARSC (2012), NECTAR (2013) and KUHMO-NECTAR (2013) conferences. Financial support from the ERC (AdG Grant \#246969 OPTION) is gratefully acknowledged. The usual disclaimer applies.
} 


\section{Introduction}

How is a tender auction affected when one bidder owns a complement or substitute to the facility that is auctioned? Such a bidder will be referred to as an "existing operator"; other bidders are "new bidders". An example of such a case is when a government tenders an airport, where one bidder could own another substitute airport in the region, or a complementing airport that is frequent destination, or a competing high-speed rail. Or, when tendering the right to supply electricity, one bidder might already supply natural gas in that region. Further examples are auctioning a telecommunication network, a utility, a public transport, or mobile-internet frequencies. ${ }^{1}$

There are two facilities that are imperfect substitutes or complements. One facility is auctioned, and the "existing operator" owns the other one. The focus is on second-offer auctions $^{2}$ with two bidders, where the winner has to match the bid of the loser. The paper extends the literature by explicitly modelling advantaged bidders in tendering where firms, in their bidding, consider the effects of the auction outcome on future competition, and by analysing the regulatory (consumer) "price auction" (where bidders compete on the price they will charge to consumers), in addition to the "standard auction" (where bidders compete on how much they will pay for the concession). We show that the effects of an existing-operator bidder differ strongly between a standard and price auction.

When the existing operator loses the standard auction, there will be duopolistic competition instead of a monopoly. Hence, an existing operator is willing to bid more aggressively, as winning means retaining the monopoly (Gilbert and Newbery, 1982). In many (parameter) settings, the existing operator always wins, and the competition for the field ${ }^{3}$ is eliminated.

Conversely, the price auction with substitute facilities is won more often by the new bidder, and thus more often leads to a duopoly, and this increases welfare. Still, with complements, the existing operator is more likely to win. But this may improve welfare as a duopoly with complements has higher prices than a monopoly due to "double marginalisation" in teh former case (Economides and Salop, 1992). The effects of an existing bidder in the standard auction are in line with those found in the related literature (e.g. Krishna and Rosenthal, 1996; Bulow et al., 1999). A new contribution of this paper is that a price auction not only raises welfare

\footnotetext{
${ }^{1}$ Related cases include takeover battles with some bidders owning part of the target (Burkart, 1995; Bulow et al., 1999); and tender auctions when one firm has information on potential customers or a well-known brand-name (Klemperer, 1998). Other examples are: dissolutions of partnerships (Cramton et al., 1987), creditors bidding in bankruptcy auctions (Burkart, 1995), heirs bidding for a family estate (Engelbrecht-Wiggans, 1994), and charity auctions (Goeree et al., 2005). In all these settings, some or all bidders receive utility from the auction revenue. Also in procurement auctions, advantages can be important. McAfee and McMillan (1989) study procurement when the two types of bidders differ in the distribution of values. In Laffont and Tirole (1993), an incumbent currently has the procurement contract, but the contract is reauctioned. If investments are non-transferable and sunk, the incumbent is more likely to win the reauction. Finally, a firm that won a previous procurement auction might have developed expertise or migth be to bsy to start a new one (e.g. De Silva, 2003).

${ }^{2}$ An auction where the winner has to match the second-best offer, seems realistic in many setting. Krishna and Rosenthal (1996) used second-offer "standard auctions" for analysing frequency auctions in mutiple regions. As they argue: if reality is best described by a first-offer setting, than our second-offer modeling can be seen as an approximation.

${ }^{3}$ I.e. the competition in the auction to become an operator with market power.
} 
directly by lowering consumer prices, it also has competition in the auction in larger parameter ranges than a standard auction, and after a price auction there more often is competition between the facilities with substitutes, and less often with complements.

In auctions on service quality or the number of users similar considerations come to play as with the price auction, and it also depends which bidder is advantaged. An auction on service quality (with a regulated price) is for example used in tendering public transport in the Netherlands (Mouwen and Rietveld, 2012), and government procurement often uses auctions where bids are scored on purchase price and quality (Che, 1993; Asker and Cantillon, 2010).

A firm's value of owning the new facility is modelled in two ways. With "private-values", firms differ in the value as they have different marginal costs, and a firm's own marginal cost is private information. With "common-values", the marginal cost is the same for both, but each has a private expectation, and updates it when it learns the other's. We will see that these two settings result in very different effects of an existing operator entering the auction.

In a "standard auction", for given demand and cost functions, the existing operator is willing to pay more than a new bidder. Hence, with private-values, the existing operator bids more aggressively and wins more often, and it always wins if there is little heterogeneity in the marginal costs or if the facilities are strong substitutes/complements. Thus, an existing-operator bidder can severely limit the competition for the field, although it often raises government revenue. This is especially important in markets with many interacting facilities (e.g. transit), as after a firm becomes an existing operator, it may win all future auctions cheaply.

These results on the standard auction are in accordance with earlier literature. Persistence of a monopoly with an existing operator has been studied by Gilbert and Newbery (1982) and Chen (2000). Krishna and Rosenthal (1996) study frequency auctions for multiple regions with local and global bidders, where the latter gain synergies if they win in multiple regions, and thus bid higher for a given value of a region's frequency. Burkart (1995) and Singh (1998) study a takeover battle of a firm where one bidder owns part of it and the second does not. The bidder who already own shares bids more aggressively and bids above its valuation of the firm, which is compensated by the fact that if it loses it gains a higher payment for its toehold shares.

Common-values give more extreme outcomes than private-values: now the existing operator always wins the standard auction. That a bidder with a tiny advantage wins with commonvalues (when the other bidder has no advantage) is a general result (see Klemperer, 1998). Bulow et al. (1999) extend this to a takeover battle with common-values and both bidders already owning shares of the target (i.e. both having an advantage). The bidder who owns more shares is advantaged in a second-offer auction, but does not always win. They also study a first-price auction, and find that it often improves the outcome for the auctioneer.

A "standard auction" only raises revenue. As Hazlett and Muñoz (2009) argue, a welfaremaximising government should also care about consumer surplus. This could be done by attracting more firms to the market or by direct regulation. Alternatively, the government could endogenously regulate via an auction on the price that will be asked to consumers, where the 
lowest offered price wins. The advantage of the price auction over direct regulation is that governments need less (or no) information on the demand and cost conditions, where such information can be costly and difficult to ascertain. A perfectly-competitive price auction leads to the first-best outcome of marginal-cost pricing; a standard auction never attains the first-best (Verhoef, 2007). ${ }^{4}$ With imperfect competition, a price auction does not result in marginal-cost pricing; but the price does approach marginal cost as the auction becomes more competitive.

With a price auction and complements, the existing operator is willing to offer a price below its marginal cost: the loss due to a lower change of winning the auctioned facility is compensated by that, when the existing operator loses, the new firm will have to set a lower price, and this raises the profit from the existing facility. Hence, with complements, the existing operator is more likely to win. With substitutes, the existing operator is less likely to win: when losing the auction, it wants a higher price on the auctioned facility to increase the profit from its existing facility. With common-values, we again find that the advantaged bidder always wins, but now who is advantaged depends: with complements the existing operator always wins, with substitutes it always loses.

In reality there will be a mix of common- and private-values. Firms do differ in their cost. But different projects also have different characteristics that affect costs in the same for all firms, and firms may differ in their expectations on this. For instance, in water-supply, the local water source may be more or less accessible, plentiful and pure, and this has the same effect on profits for all. Different from our setting with heterogeneous costs, firms could also differ in the demand function they will face. The qualitative results of this paper would then also hold.

Section 2 presents the general set-up of the model. Section 3 studies the standard auction under private-values, and Section 4 under common-values. Sections 5 and 6 discuss the price auction. Section 7 gives a numerical illustration, Section 8 discusses some caveats to the research, and finally Section 9 concludes.

\section{General set-up}

The two facilities are imperfect substitutes or complements. Facility $A$ is auctioned; the existing operator owns facility $B$. The game is timed as follows: first the bidders learn their private signals (which determine the marginal costs), then they bid in the auction and the government selects the winner, and finally the operators set their prices in a Bertrand fashion. In its bidding, the existing operator considers how winning or losing the auction will affect future competition. We ignore the preceding period where there was only facility $B$. We study second-offer auctions, where the winner should at least match the loser's offer; with two bidders, the ascending and sealed-bid versions of this auction are equivalent (see, e.g., Krishna,

\footnotetext{
${ }^{4}$ Perfect competition seems unlikely in an auction: in reality, costs and demands do vary over firms (Gómez-Ibáñez and Meyer, 1993) and there seems to be substantial uncertainty (Flyvbjerg et al., 2003, 2007; De Silva et al., 2003). Moreover, there are often a limited number of bidders.
} 
2010), so this distinction is ignored. Thus with the price auction, the winner cannot set a price above the offer of the auction loser. When a tie occurs, the winner is determined by a coin flip.

\subsection{Price setting}

The number of users of facility $i=A, B$ is denoted $q_{i}$; its price is $p_{i}$. Inverse demand for facility $i$ follows (where subscript $j$ indicates the competing facility) ${ }^{5}$

$$
p_{i}=d_{0}-d_{1} \cdot q_{i}+d_{2} \cdot q_{j}
$$

For convenience, the demand parameters are assumed to be the same for the two facilities. Demand decreases with the own price, and hence $d_{1}>0$. For substitutes, demand increases with the other facility's price, and thus $d_{2}<0$; the opposite holds for complements. Assuming away income effects, consumer surplus is the line-integral of the two demands. Welfare is the sum of consumer surplus, profits and government revenue; and thus the shadow cost of public costs is assumed to be 1 .

In duopoly, each firm maximises its profits given the other's price. As the facilities are not perfect substitutes, the firms make a profit even though they compete on prices. The marginal cost of $A$ for bidder $k$ is $m c_{k, A}$. On $B$, the marginal cost for the existing operator is $m c_{B}$. The duopolistic price set by a new-bidder firm on facility $A$, for a given price on $B$ of $p_{B}$, is

$$
p_{N, A}^{* *}=\frac{d_{0}+d_{2} p_{B}+d_{1} \cdot m c_{k, A}}{2 d_{1}},
$$

where subscript $N$ indicates the New bidder, ${ }^{* *}$ a duopoly, and ${ }^{*}$ will indicate a monopoly. For facility $B$, the duopolistic price set by an existing operator for a given price on $A$ of $p_{A}$ is

$$
p_{E, B}^{* * *}=\frac{d_{0}+d_{2} p_{A}+d_{1} \cdot m c_{B}}{2 d_{1}},
$$

where subscript $E$ indicates the existing operator. The Nash-equilibrium prices, and thus profits, are easily obtained from this equation.

If the existing operator controls $A$ and $B$, there is a monopoly. The price equation for $A$ (for given $p_{B}$ ) is (and similarly for $B$ )

$$
p_{E, A}^{*}=\frac{d_{0}+d_{2} p_{B}+d_{1} \cdot m c_{E, A}+d_{2}\left(p_{B}-m c_{B}\right)}{2 d_{1}} .
$$

With substitutes $b_{2}>0$, and hence the monopolistic prices are higher than the duopolistic ones. With complements $b_{2}<0$, and a duopoly leads to higher prices than a monopoly, as a duopolist ignores that its mark-ups lower the profit of the other firm (Economides and Salop, 1992).

\footnotetext{
${ }^{5}$ Following standard micro-economics $d_{l} \cdot d_{l}>d_{2} \cdot d_{2}$.
} 


\subsection{Marginal cost}

Before the auction, bidder $k$ gets private information from a signal $t_{k}$ (from nature). With private values, this $t_{k}$ determines its marginal cost and thereby bid. With common-values, the (expected) marginal cost also depends on the other bidder's signal, which is unknown before the auction but is learned by the auction winner. The signal of both bidders is drawn from the same (uniform) distribution that ranges between zero and one. The distribution function is $F[t]$, the density function $f[t] \equiv \partial F[t] / \partial t$.

With private-values, the marginal cost on $A$ decreases with the bidders signal, $t_{k}$, following

$$
m c_{A, k}^{p}\left[t_{k}\right]=m c_{\max }^{p}-r \cdot t_{k}
$$

where superscript ${ }^{p}$ indicates private-values, $m c_{\max }^{p}$ is some assumed maximum marginal cost with private-values, and $r$ a positive parameter. The profit from A will be determined by this marginal cost, the price on B and the price on A, where the price on A follows (2) or (3) after the standard auction and is determined by the loser's bid after the price auction. pricing rule

Common-values illustrates when firms differ in what they expect marginal cost will be, and update their expectance when they learn the other firm's. The resulting marginal cost after the auction linearly decreases in the signals of bidders $k$ and $j$ :

$$
m c_{A, k}^{c}\left[t_{k}+t_{j}\right]=m c_{\max }^{c}-\frac{r}{2}\left(t_{k}+t_{j}\right)
$$

where superscript $c$ indicates common-values. Hence, the resulting marginal cost will depend on the average of the two signals. Again, the profit on A depends on this resulting marginal cost, and the prices.

\section{Standard auction and private values}

This is the point to explain that our set-up implies four distinct model set-ups. Section 3 will look at the standard auction under private value, and Section 4 under common-values. Section 5 will turn to a price auction under private-values, and Section 6 under common-values.

\subsection{Bidding without an existing operator bidder}

We will start by analysing the standard auction with private values, while the next section does this with common-values and the two thereafter focus on the price auction. We first investigate two new bidders competing for $A$, whereas the existing operator owns $B$. This set-up introduces the model and helps study the effects of the existing operator entering the auction. In general, with a second-offer auction without an existing operator, a bidder offers its value (Burkart, 1995; Klemperer, 1998), and at that offer it makes a zero profit. Both after the standard as the price auction, the existing operator will set the duopolistic price following (3) on $B$, although the price set on $A$ will differ between the two auctions, and thus the equilibrium price on $\mathrm{B}$ will also differ. 
The duopolistic profit from $A$ for bidder $k\left(\Pi_{A}^{* *}\left[t_{k}, t_{j}\right]\right)$ increases in its signal as this lowers its marginal cost. Assuming that the bidding strategies are the same for both, it is optimal for a new firm $k$ to offer to transfer $\left(T_{k}^{p}\right)$ its entire profit as its bid (this profit may be negative, which is common with, for instance, public transport):

$$
T_{k}^{p}\left[t_{k}\right]=\Pi_{A}^{* *}\left[m c_{A, k}^{p}\left[t_{k}\right]\right],
$$

where superscript ${ }^{p}$ indicates private-values, and ${ }^{* *}$ a duopolistic market. To see why, suppose $k$ offered a slightly higher transfer instead: nothing changes if it won before and still wins (it still pays $j^{6}$ s offer) or if $k$ still loses; but, if $k$ lost before and now wins, its payment for the facility will be above its profit, and $k$ has a negative pay-off. If $k$ would bid lower, it would be worse off if it just won the auction before, and now loses it. From these equations it is simple to calculate the expected payments, as well as the expected profits and consumer surplus.

\subsection{Private-values and a standard auction with an existing operator}

Now we consider the existing operator entering the standard auction. The new bidder bids as just explained: it offers the entire duopolistic profit it would make from facility $A$. Given the signals, the existing operator has a higher value and bids more than the duopolistic profit from the new facility: if it wins, it is a monopolist; when it loses, a duopolist.

Lemma 1: If the existing operator wins the auctioned facility $A$, this raises the profit from the existing facility $B$ unless the two markets are independent. In this case, the monopolistic profit it attains from $A$ is also higher than the duopolistic profit that a new bidder would get. The stronger complements or substitutes the facilities are, the larger the profit gains.

Proof: This lemma is straightforward, and thus a full proof is omitted. The intuition is that if the existing operator wins, it sets the monopolistic prices; if it loses, each operator sets the duopolistic prices. The differences between the duopolistic and monopolistic prices increase with the strength of substitution/complementation.

In Nash equilibrium, the existing operator knows the bidding strategy of the new firm. We use subscript $E$ to indicate the existing operator, and $N$ indicates the new bidder. With a standard auction, the existing operator chooses to emulate a new bidder's bid with a certain signal $t_{N}$; the chosen signal to emulate in turn defines the bid, and it is set to maximise the expected pay-off. ${ }^{6}$ This emulated signal will be referred to as $t$. The objective function is

$$
O_{E}=\left(\Pi_{A}^{*}\left[t_{E}\right]+\Pi_{B}^{*}\left[t_{E}\right]\right) F[t]-\int_{0}^{t} T_{N}[x] \cdot f[x] d x+\int_{t}^{1} \Pi_{B}^{* *}[x] \cdot f[x] d x
$$

\footnotetext{
${ }^{6}$ Such maximisation of expected profit via what action to copy from the competitor's bid function is in this setting simpler than maximisation via the bid conditional on the other's bid function, but the two methods are mathematically equivalent.
} 
where the first term is the expected monopolistic profit from wining the auction, the second is the expected transfer paid (i.e. the expected second-highest offer conditional on winning), and the third term is the expected duopolistic profit from $B$ when losing.

Proposition 1: With private-values and given signals, the existing operator bids a higher transfer than a new bidder, unless the two markets are independent.

\section{Proof: Differentiating (8) to $t$ gives}

$$
\frac{\partial O_{E}}{\partial t}=0=\left(\Pi_{A}^{*}\left[t_{E}\right]+\Pi_{B}^{*}\left[t_{E}\right]-\Pi_{B}^{* *}[t]\right) f[t]-T_{N}[t] \cdot f[t]
$$

where the term between brackets gives the profit gain from being a monopolist instead of a duopolist. This gain is larger than the profit a new bidder would make (see Lemma 1); therefore, the existing operator offers a higher transfer (i.e. payment to the government), and emulates a $t_{N}$ that is above its own signal. Thus, it bids to pay more than a new bidder with the same signal as the existing operator, and thus bids above the duopolistic profit at $m c_{A, E}^{p}\left[t_{E}\right]$. This occurs unless we have two independent markets, as then the profit gain equals the profit on $A$ that a new bidder would also make. Thus just as the new bidder, the existing operator offers to pay the value of winning the new auction, the argument why this strategy maximises expected surplus is the same as for a new bidder.

The existing operator is, for given signals, willing to pay more for owning the facility as this ownership also raises the profit of its other facility. This holds for any distribution of signals.

This raises the question what the bidding is when the existing operator always wins. If $t_{E}$ is really high, the new bidder can never outbid the existing operator, and $f[t]$ in (9) will be zero. The existing operator could then offer any payment above $T_{N}[1]$ (the new bidder's offer when $t_{N}=1$ ). Figure 1 illustrates the bidding using the numerical example (as will be introduced in Section 7); the left panel does this for substitutes, and the right for complements. The general shapes of the curves are the same for any uniform distribution of signals and substitute/complement facilities. ${ }^{7}$ In the figure, with substitutes, the existing operator always wins if its signal $t_{E}$ is above 0.66 , and it is assumed that the existing operator then still offers its profit gain (which is a weakly dominant strategy). The outcome is independent of the existing operator's choice here, as it always wins and pays the new bidder's offer.

The outcome does depend on what happens when new bidder's signal $t_{N}$ is so low that it never wins (e.g. in Figure 1 for substitutes, when $t_{N}<0.35$, the new bidder's offer is always below the existing bidder's). This is because when the new firm loses, its bid determines what the existing operator will transfer. The example assumes that the new bidder still offers its profit, which is a weakly dominant strategy. If the new bidder followed a different strategy (or

\footnotetext{
${ }^{7}$ See Krishna and Rosenthal (1996) for the effects of non-uniform distribution on a standard auction in the related case.
} 
did not enter due to bidding $\operatorname{costs}^{8}$ ) the expected transfer would differ, whereas welfare is unaffected if the value of governmental revenue is one as the existing operator wins regardless of the new bidder bid and sets the same prices.

Figure 1: Offered transfer with substitutes (left) and complements (right)in the numerical example
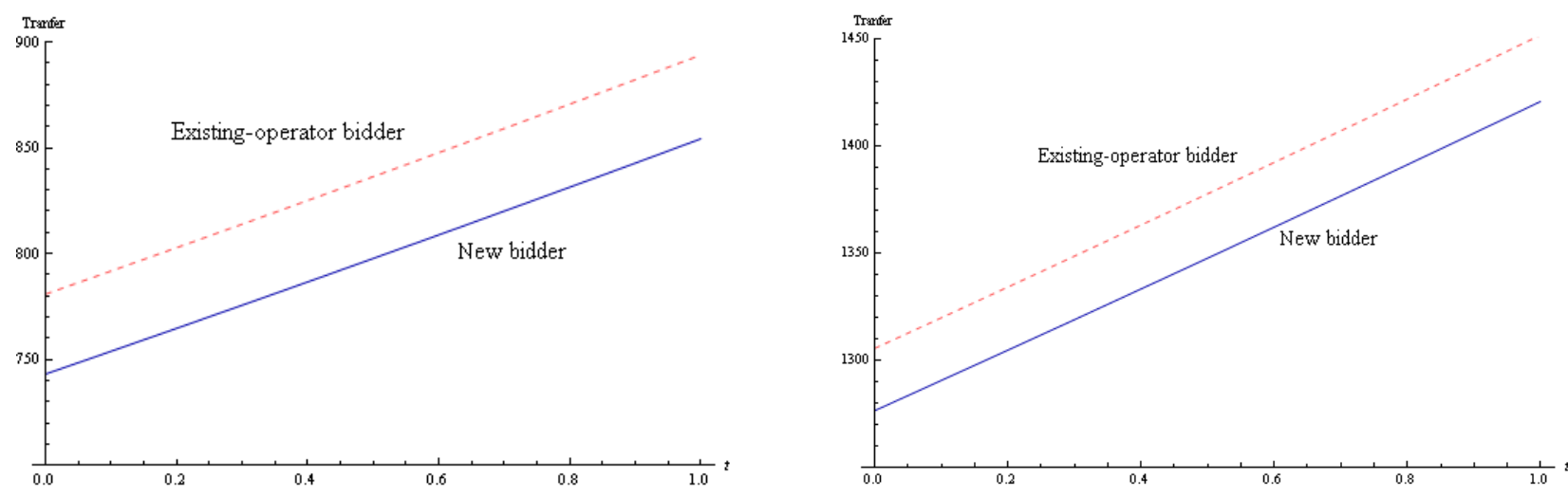

Proposition 2: If the new bidder always bids following (7) and the existing operator follows (9) (which are (weakly) dominant strategies), then expected revenue for the government from the auction is higher with the existing operator and one new bidder than with two new bidders. The new bidder is worse off.

Proof: Comparing (7) and (9) its shows that, for a given signal, the existing operator bids higher than a new bidder; whereas the bid of a new bidder is unaffected by the presence of an existing operator in our second-offer auction (as it wins it faces the same duopoly after the auction regardless of type of competitor in the standard auction). Thus, the payment if the new bidder wins is increased, while the payment when existing operator wins equals the offer of the new bidder whose bid function is unchanged. Hence, the expected revenue is higher. A new bidder is worse off with an existing operator bidder, as it is less likely to win and pays more when it does.

This again assumes that a new bidder always follows (7) and enters the auctions. Even though, if it has a very low signal and can never win, it would be equally profitable not to enter (and more so if there are bidding costs).

The findings in propositions 1 and 2 are similar to those in the literature on for instance "global bidders" who can attain synergies in multiple auctions (Krishna and Rosenthal, 1996), and in takeover battles with bidders who already own shares (Burkart, 1995; Singh, 1998). Also there, the global/share-owning bidder bids higher for given signal, because its bidding considers a second effect. Here, this is the profit gain on the existing facility when winning the auctioned one; with global bidders, it is the synergies attained when winning multiple items;

\footnotetext{
${ }^{8}$ See, for instance, Mougeot and Naegelen (2005) on a study on a tender auction with an entry choice and the determinants of the optimal number of entrants.
} 
and, in the take-over setting, it is the profit from the owned shares when losing. This in turn raises auction revenue and hurts the other bidders. Different from Krishna and Rosenthal (1996), the bidding function of the existing operator is continuous for any distribution of the signals, while in their global bidder's bid function may be discontinuous.

The results are sensitive to the heterogeneity in the marginal cost, and how strong a substitute/complement the facilities are. Less heterogeneity means that an advantaged bidderdefined as the one that is more likely to win-wins more often, as the signal difference in favour of the disadvantaged needs to be even larger for it to win. For a low amount of heterogeneity, the disadvantaged bidder can never win. Also with very strong complements/substitutes, the profit gain for existing facility $B$ is so large that the existing operator will always outbid the new bidder. The likelihood of existing operator winning increases the stronger complements/substitutes the facilities are, as the profit gain from being a monopolist is larger.

Under substitutes, expected welfare is lower with an existing operator bidder as it often leads to a monopoly; under complements, expected welfare is higher as the more harmful duopoly with double marginalisation is sometimes replaced with a monopoly.

\section{Common-values and a standard auction}

\subsection{Two new bidders}

We again start with the strategies of two new bidders. Just as with private values, on $B$ the price set by the existing operator after the auction follows (3). After the standard auction, the winner sets the duopolistic price on $A$ of (2) (although marginal cost now equals (6)).

The duopolistic profit from $A$ for bidder $k\left(\Pi_{A}^{* *}\left[t_{k}, t_{j}\right]\right)$ increases in both signals. It is optimal for $k$ to offer to transfer its entire profit when $t_{j}=t_{k}$ :

$$
T_{k}^{c}\left[t_{k}\right]=\Pi_{A}^{* *}\left[t_{k}, t_{k}\right]
$$

where superscript ${ }^{c}$ indicates common-values, and ${ }^{*}$ a duopolistic market. Just as with privatevalues, any other offer would lower the expected pay-off.

\subsection{Example of a bidder with an advantage}

With common-values, the bidder with the advantage always wins. The intuition behind this is that whenever a disadvantaged bidder wins this is bad news as the other bidder must be very pessimistic about the value (and this other bidder's belief also determines resulting value of what is auctioned). Whenever the disadvantaged bidder would win, it would face a winner's curse and pay more than the value of what is auctioned. This result can be illustrated by an example following Klemperer (1998) where the value of winning is just the sum of the two signals $t_{k}+t_{j}$, but the advantaged firm has a tiny extra value $\alpha>0$.

In Klemperer's setting, without advantages (i.e. $\alpha=0$ ) the bidder with the highest signal wins, and each bidder $k$ bids twice its signal: $t_{k}+t_{k}$. Suppose, $k$ would bid $\varepsilon$ higher. If $k$ won the 
auction before nothing changes, it still pays $j$ 's bid of $t_{j}+t_{j}$. But if $k$ now just wins, then the other bidder $j$ signal's $t_{j}$ must follow $t_{k}<t_{j}<t_{k}+\varepsilon$, and thus the common-value of the good of $t_{j}+t_{k}$ will be below $k$ 's payment of $t_{j}+t_{j}$ (as $t_{j}>t_{k}$ ), and thus $k$ makes a loss. Hence, bidding $\varepsilon$ higher lowers the expected pay-off. Similarly, bidding lower is also not profitable.

The disadvantaged firm $d$ with signal $t_{d}$ is willing to pay its common-value of $t_{a}+t_{d}$ (note that it does not know $t_{a}$, but it will have a belief about it), while the other is willing to pay its value $t_{a}+t_{d}+\alpha$. Suppose the disadvantaged bidder followed the same strategy as without advantages, and bids twice its signal: $t_{d}+t_{d}$. If it wins, this would be bad news: then the signal of the advantaged bidder must be very low and follow $t_{a} \leq t_{d}-\alpha / 2$, and thus the value of the good is below $t_{a}+t_{d}-\alpha / 2$, which is less than the bid. Hence, whenever the disadvantaged bidder wins using this strategy, it makes a loss. To overcome this, the disadvantaged bidder must alter its strategy and shade its bid. But knowing this, the advantaged can bid more aggressively, which in turn implies that the disadvantaged must shade its bid even more, and so on until the disadvantaged always bids as if the advantaged bidder's signal is zero and thus the commonvalue of the item is the lowest possible given its signal. Hence, the disadvantaged bidder never wins, and the advantaged always wins at a low payment.

\subsection{Standard auction with an existing bidder and common-values}

Also with our tender auction the advantaged always wins, which can be proven using a discussion along the same lines as the example. Hence, this proof is not given in detail.

Proposition 3: In a standard auction and common values, the existing operator always wins the auction (unless demands for the facilities are independent).

For given signals, the new bidder could offer the expected duopolistic profit from $A$, the existing operator could offer the expected profit from $A$ plus the profit gain on $B$ due to being a monopolist. Hence, a new bidder has to bid as if the existing operator has a signal of zero, and thus as if the marginal cost on A would be the highest possible given the new bidder's signal. Hence, the existing operator always wins cheaply and has a substantial profit, and its presence lowers the governmental revenue. All this is unless the demands are independent, as then there are two independent markets and for given signals the value of facility $A$ is the same for the new and existing bidder. Hence, then there are just two standard bidders.

\section{Price auction and private-values}

This section focuses on the price auction under private values, where the lowest offered price wins and the winner can set a price on $A$ that is not above the loser's bid. With a standard auction, the auction winner will have substantial market power and this hurts consumers and welfare. The competition in the price auction drives down the prices that will be set, and with perfect competition in the auction the price on $A$ would equal marginal cost. A new bidder bids, 
just as before, such that at its bid it would make a zero profit: its offered price thus equals its marginal cost. With substitutes, the existing operator is at a disadvantage: it offers a price that leads to profit from $A$ : its bidding not only considers the expected profit when winning, but also that, when losing, a higher offered price means that the new firm will set a higher price on $A$ and this in turn raises the existing operator's profit on $B$. Conversely, with complements, the existing operator offers a price below its marginal cost and is thus more likely to win.

\subsection{Two new bidders in a price auction}

With two new bidders, the existing operator always faces a duopoly after the auction and sets its price following (3). A new bidder $k$ offers a price equal to marginal cost on $A$ following (5), such that at that offer it would make a zero profit:

$$
p_{A, k}^{c}=m c_{A, k}^{c}\left[t_{k}\right]=m c_{\max }^{p}-\frac{r}{2}\left(t_{k}\right) .
$$

Offering a lower price than (11) might lead $k$ to win the auction if $j$ 's signal is slightly higher than $k$ 's, and then $k$ would have to set the price below marginal cost. Hence, this alternative strategy is not profitable.

\subsection{A price auction with an existing operator bidder}

The objective function for the existing operator with a price auction and one other new bidder is similar as with the standard auction. The existing operator chooses to emulate a new bidder's bid with a certain signal $t_{N}$. This emulated signal is referred to as $t$. Choosing a higher $t$ will mean a lower offered price, a higher chance of winning, but also when losing a lower price on the competing facility. The chosen $t$ maximises its pay-off function:

$$
O_{E}=\int_{0}^{t}\left(\Pi_{A}^{*}\left[t_{E}, p_{A, N}^{p}[x]\right]+\Pi_{B}^{*}\left[t_{E}, p_{A, N}^{p}[x]\right]\right) \cdot f[x] d x+\int_{t}^{1} \Pi_{B}^{* *}\left[p_{A, N}^{p}[t]\right] \cdot f[x] d x ;
$$

where the first integral gives the expected profit when winning $A$, and the second when losing. The $p_{A, N}^{p}[t]$ is the price the new firm offers when its signal is $t$. The profit when winning depends on the existing operator's signal $\left(t_{E}\right)$ —as this determines its marginal cost —and the loser's signal —as this determines the price it may set on $A$. The profit on $B$ when losing ( $\left.\Pi_{B}^{* *}\right)$ only depends on the price offered by the existing operator and thus on the chosen $t$.

The f.o.c. of the existing operator's choice is ${ }^{9}$

$$
\frac{\partial O_{E}}{\partial t}=0=\left(\Pi_{A}^{* *}\left[t_{I}, p_{A, N}^{p}[t]\right]+\Pi_{B}^{*}\left[t_{E}, p_{A, N}^{p}[t]\right]-\Pi_{B}^{* *}\left[p_{A, N}^{p}[t]\right]\right) f[t]+(1-F[t]) \frac{\partial \Pi_{B}^{* *}}{\partial p_{A}} \frac{\partial p_{A, N}^{p}[t]}{\partial t} ;
$$

where the term between brackets gives the profit gain due to winning $A$. The second term is for when losing the auction, and gives the increase in profit from $B$ due to a marginal increase in $t$.

\footnotetext{
${ }^{9}$ This equation will have two solutions but only one of those is local maximum; for very strong substitutes even that solution is not a real number between zero and one.
} 
With complements, the second term is negative as a higher $t$ means that the losing price offer is higher and thus the new firm can set a higher price on $A$ and this lowers the profit from complement facility $B$. With substitutes, the second term is positive.

Proposition 4: If (13) has a real solution, with complements and given signals, the existing operator who follows (13) offers a lower consumer price than the new firm would, $t>t_{E}$, and is thus more likely to win. Conversely, with substitutes and given signals, the existing operator bids a higher price. Still, in many cases, the existing operator is better off using the alternative strategy of offering the monopolistic price and thus never winning.

Proof: We will first consider complements. Assume that instead of the proposed strategy, the existing operator follows the same strategy as a new bidder, and thus set $t=t_{E}$. Then, the first term of (13) equals zero, ${ }^{10}$ while the second term is positive if $t_{E}<1 .{ }^{11}$ To equate the f.o.c. of (13) to zero, $t$ then has to increase, ${ }^{12}$ and this means that it offers a price below marginal cost. The exception is at $t_{E}=1$, as then the second term in (13) is zero as $1-F[t]=0$, and thus the existing operator gives the same offer as a new bidder would: $p_{A, N}^{p}[1]=p_{A, E}^{p}[1]$.

With substitutes, $t$ should be smaller than $t_{E}$. At $t=t_{E}$, the first term of (13) is zero and the second is negative, because, with substitutes, the profit from $B$ increases with the price of $A$, instead of decreasing as with complements.

Figure 2: Offered consumer price's with substitutes (left) and complements (right)
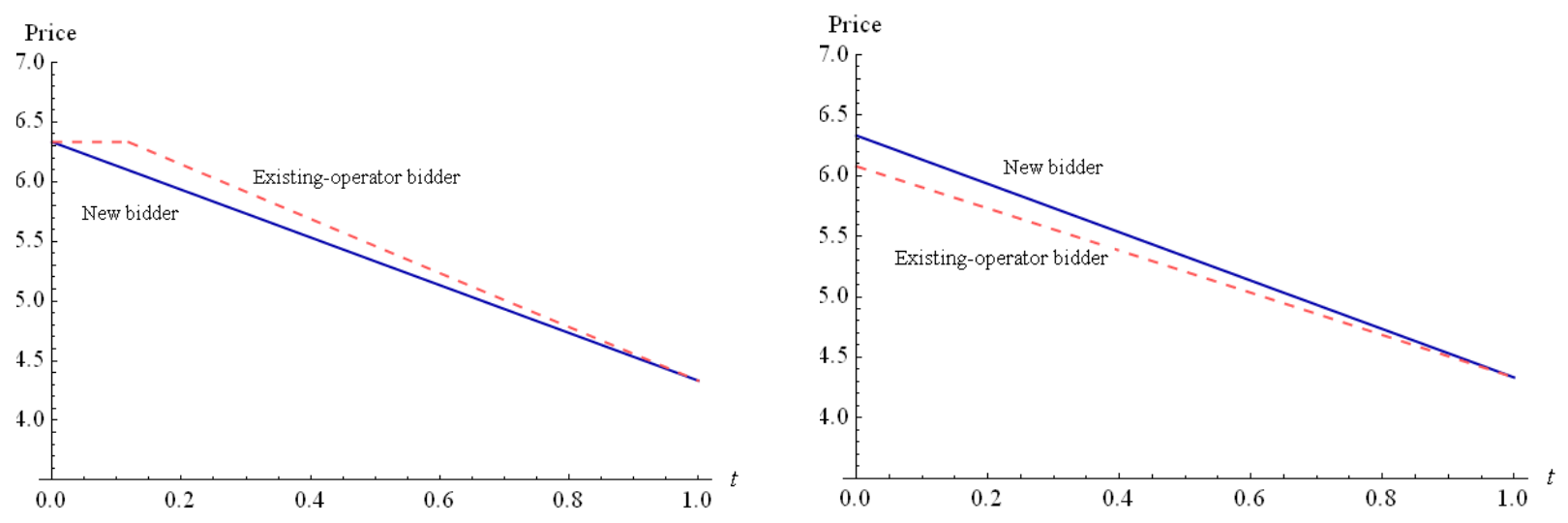

The existing operator has two concerns: the profit from the auctioned facility and the profit of its existing facility; the new bidder only has the former concern. With complements, the existing operator is willing to offer a lower price, as a lower price also raises the demand for its other facility. Instead, with substitutes, it offers a higher price, as a higher price on the

\footnotetext{
${ }^{10} \Pi_{A}^{*}\left[t_{E}, p_{A, N}^{p}\left[t=t_{I}\right]\right]=0$, as the existing operator would offer a price equal to marginal cost; and $\Pi_{B}^{* * *}\left[t_{E}, p_{A, N}^{p}\left[t=t_{I}\right]\right]=$ $\Pi_{B}^{*}\left[p_{A, N}^{p}\left[t=t_{E}\right]\right]$ : the profit from $A$ is always zero, and thus it is optimal for $B$ 's price on $B$ to only maximise $B$ 's.

${ }^{11}$ Then $1-F[t]>0$, whereas the other two terms are negative: the profit from $B$ decreases in $A$ 's price with complements $\left(\partial \Pi_{B}^{*} / \partial p_{A}<0\right)$, and the price offer of the new bidder decreases in its signal $\left(\partial p_{A, N}^{p}[t] / \partial t<0\right)$.

${ }^{12}$ This makes the first term in (13) negative and the second term less positive (as $1-F[t]$ becomes smaller and $\partial \Pi_{B}^{*} / \partial p_{A}$ less negative).
} 
auctioned substitute raises the demand for its existing facility. Different from the earlier literature, in this setting it can occur that the bidder who therefore bids strategically is not the one that is more likely to win. To illustrate the setting, Figure 2 gives the bidding in the numerical example (as presented below). Just as with the standard auction, the general shape of the curves holds for any parameterisation with a uniform distribution of signal.

If the bidders follow (11) and (13), less heterogeneity means that an advantaged bidderdefined as the one that is more likely to win-wins more often, as the signal difference in favour of the disadvantaged needs to be even larger for it to win. For a low amount of heterogeneity, the disadvantaged bidder never wins. A larger cross sensitivity parameter (i.e. weaker substitutes or stronger complements) lowers the chance that the existing operator wins the auction, as for given signals eq. (13) leads to a higher price offer.

With an existing operator, for the price auction to work, the government has to set a maximum price-offer that is allowable (i.e. impose a reserve). Otherwise the existing operator is typically better off by bidding the unregulated duopolistic price instead of following (13). Thereby, it always loses the auction, but gains a much better outcome for $B$, which often raises its total profit. Hence, the government has to ensure that the existing operator bids seriously. An obvious candidate for this maximum is the highest possible marginal cost, and this is also used in the example (in Figure 2 (left panel) this explains the horizontal section of the dashed bidding curve, as there the constraint is binding). A slightly higher maximum price has no effect with complements, as then the existing operator still prefers to bid below its marginal cost. However, with substitutes a slightly higher maximum price-offer does have an effect. For the range of $t_{E}$ where the existing operator can never win, the best it can do is offer the highest possible price, and thus then a higher maximum price-offer thus lowers welfare.

\section{Price auction and common-values}

Turning to the final case of a price auction with common values, we will see that again the advantaged bidder always wins. But now the advantage depends: with complements, the existing operator bidder always wins; with substitutes, the new bidder always wins.

We will start with the strategies with two new bidders. Bidder $k$ offers a price equal to marginal cost when $t_{j}=t_{k}$, such that it then makes a zero profit:

$$
p_{A, k}^{c}=m c_{A, k}^{c}\left[t_{k}+t_{k}\right]=m c_{\max }^{c}-\frac{r}{2}\left(t_{k}+t_{k}\right)=m c_{\max }^{c}-r \cdot t_{k} ;
$$

Just as before, any other offer would lead to a lower expected pay-off.

The existing operator in its bidding also considers the effects, when it loses, on the price set on $A$ by a new bidder and the resulting effects on the profit on $B$. With complements, the profit on $B$ decreases if the price on $A$ is set higher, and thus the existing operator is willing to offer a price below its marginal cost. Conversely, with substitutes, a higher price on $A$ raises the profit on $B$, and thus the existing operator is only willing to bid bids a price above its marginal cost. 
Proposition 5: Consider a price auction with common-values and given signals. With complements, the existing operator could offer a lower price and thus always wins; with substitutes, it could offer a higher price and always loses.

Again, the proposition can be proven using an argument similar to for the simplified example.

\section{Numerical illustration}

Now we turn to numerical illustration. It is important to look at an example: the analytics can show that having an existing operator matters, but the question that remains is how much? Table 1 introduces the parameterisation. There are two cases: substitute and complement facilities. The marginal cost on $B$ is 5 . On $A$, the marginal cost has a range of 2; and, with two new bidders, the mean of the winner's marginal cost is 5 . The signals are IID and uniformly distributed between zero and one.

Table 1: Parameterisation of the illustration

\begin{tabular}{lc}
\hline Parameter & Value \\
\hline$d_{0}$ & $115 / 5$ \\
$d_{1}$ & $-4 / 15$ \\
$d_{2}$ & $-1 / 15$ (substitutes) or $1 / 15$ (complements) \\
$r$ & 2 \\
$m c_{\max }^{p}$ & $6+1 / 3$ \\
$m c_{\max }^{c}$ & 6 \\
$m c_{b}$ & 5 \\
\hline
\end{tabular}

\subsection{A standard auction}

Table 2 tabulates the expected outcomes ( $\mathrm{E}[x]$ gives the expectation of $x$ ) of a standard auction with two new bidders. Table 3 looks at the case with an existing bidder. ${ }^{13}$ It compares the effects under substitutes versus complements and private-values versus common-values. The calibration is such that outcomes with two new bidders are very similar under private- and common-values as the expected marginal cost of the winner is in both cases 5 . This helps illustrate how different the effects are of an existing operator in these two cases. In the tables, the relative efficiency of a policy is the welfare gain from the base case (when there is no supply of $A$, and $B$ has a monopolistic price) relative to the gain from going to first-best marginal-cost pricing on $A$ and $B$.

With private-values, the existing operator is willing to pay more for a given signal than the new bidder. The existing operator thus wins more often, but may have to pay a higher transfer than the profit from $A$. Let the existing operator's surplus equal expected profit on A and B minus expected payment. Then, its surplus is lower than, with two new bidders, the expected

\footnotetext{
${ }^{13}$ The results are attained by using the analytical bidding and price-setting rules, and then solving for the resulting outcomes conditional on the winner's and loser's signal, and finally integrating over all possible signals to get the expectations.
} 
profit on B plus a new bidder's surplus. This holds unless the new bidder can never win, which occurs if the facilities are strong complements/substitutes or if there is little heterogeneity.

With common-values, the existing operator always has a higher surplus than, with two new bidders, the sum of a new bidder's surplus and the profit on $B$. The results assume that the new bidder still bids its value and thus offers the profit it would make under $t_{E}=0$. This may not be realistic, as the new bidder has no chance of winning, and thus, if there are the tiniest bidding costs it would never enter the auction. Then, our results are more extreme: the same prices would be set, but the transfer would be zero.

Table 2: Expected outcome a standard auction and two new bidders

\begin{tabular}{|c|c|c|c|c|}
\hline & \multicolumn{2}{|c|}{ Substitutes $\left(d_{2}=-1 / 15 \approx-0.067\right)$} & \multicolumn{2}{|c|}{ Complements $\left(d_{2}=1 / 15 \approx 0.067\right)$} \\
\hline & Private-values & Common-values & Private-values & Common-values \\
\hline $\mathrm{E}[$ Price of $A]$ & 19.29 & 19.29 & 23.52 & 23.52 \\
\hline $\mathrm{E}[$ Price of $B]$ & 19.31 & 19.29 & 23.50 & 23.52 \\
\hline Prob. $i$ wins & 0.5 & 0.5 & 0.5 & 0.5 \\
\hline E[Consumer Surplus] & 1088.5 & 1088.5 & 1097.5 & 1097.5 \\
\hline $\mathrm{E}[$ Transfer by $i]$ & 389.7 & 399.0 & 661.9 & 673.9 \\
\hline $\mathrm{E}[\text { Profit for } i \text { from } A]^{\#}$ & 408.3 & 408.1 & 686.0 & 685.8 \\
\hline $\mathrm{E}[$ Profit from $B]$ & 816.3 & 816.3 & 1371.8 & 1371.7 \\
\hline $\mathrm{E}$ [Welfare] & 2721.4 & 2721.0 & 3841.2 & 3840.8 \\
\hline Relative efficiency $^{*}$ & 0.654 & 0.654 & 0.571 & 0.571 \\
\hline
\end{tabular}

Note: * relative efficiency of a policy is the welfare gain from the base case (when there is no supply on $A$, and $B$ has a monopolistic price) divided by the gain from going to first-best pricing on $A$ and $B .{ }^{\#}$ The profit includes the transfer that will be given to the government.

Table 3: Expected outcome a standard auction and an existing bidder

\begin{tabular}{lc|c|c|c}
\hline & \multicolumn{2}{c|}{$\begin{array}{c}\text { Substitutes }\left(d_{2}=-1 / 15 \approx-0.067\right) \\
\text { Private-values }\end{array}$} & $\begin{array}{c}\text { Complements }\left(d_{2}=1 / 15 \approx 0.067\right) \\
\text { Private-values }\end{array}$ & Common-values \\
\hline E[Price of $A]$ & 20.10 & 21.67 & 21.77 & 21.67 \\
E[Price of $B]$ & 20.03 & 21.67 & 21.74 & 21.67 \\
Prob. $N$ wins & 0.21 & 0 & 0.31 & 0 \\
E[Consumer Surplus] & 821.1 & 833.4 & 1273.4 & 1389.0 \\
E[Transfer by $N]$ & 173.0 & 0 & 422.8 & 0 \\
E[Transfer by $E]$ & 620.0 & 788.5 & 913.0 & 1335.6 \\
E[Profit for $N$ from $A]^{\#}$ & 178.0 & 0 & 431.7 & 0 \\
E[Profit for E from $A]^{\#}$ & 352.3 & 833.5 & 667.9 & 1389.1 \\
E[Profit from $B]$ & 830.5 & 833.3 & 1383.5 & 1388.9 \\
E[Welfare] & 2476.1 & 2500.2 & 4040.4 & 4167.0 \\
Relative efficiency & 0.516 & 0.53 & 0.621 & 0.65 \\
\hline \multicolumn{4}{r}{ Note: ${ }^{\#}$ The profit includes the transfer that will be given to the government. }
\end{tabular}

\subsection{A price auction}

We now turn to the price auction. As discussed the price auction leads to a much higher welfare than a standard auction, as it limits the price on A. Table 4 gives the results with two new bidders, and Table 5 with an existing operator.

As discussed, with an existing operator, the price auction needs a maximum price-offer that is allowed (i.e. impose a reserve). Otherwise the existing operator is typically better off by bidding the unregulated duopolistic price instead. A somewhat higher maximum-price has no effect with complements, but with substitutes it lowers welfare as an existing operator with a 
very high marginal cost will always bid the maximum price-offer. But the loss might not be that large: in the example with private-values, when we compare the reserve $p_{A} \leq m c_{m a c}$ with when the existing operator can set the duopolistic price when $t_{E}$ is below the critical value (but not when it is above it), the latter has a welfare that is $1 \%$ lower. The welfare from a realistic reserve (which ensures that the existing operator bids seriously) is in between these two cases; and thus the loss from a higher maximum might be limited.

Moreover, with substitutes and private-values, even a price auction without a reserve does better than the standard auction: it always leads to an unregulated duopoly, whereas the standard auction leads to a monopoly $79 \%$ of the time. The price auction is also less affected by an existing operator bidder under private-values: for the price auction welfare is only slightly higher with two new bidders, whereas with the standard auction the effect can be large.

Table 4: Expected outcome a price auction and two new bidders

\begin{tabular}{lc|c|c|c}
\hline & \multicolumn{2}{c|}{ Substitutes $\left(d_{2}=-1 / 15 \approx-0.067\right)$} & \multicolumn{2}{c}{ Complements $\left(d_{2}=1 / 15 \approx 0.067\right)$} \\
& Private-values & Common-values & Private-values & Common-values \\
\hline E[Price of $A]$ & 5.67 & 5.33 & 5.67 & 5.33 \\
E[Price of $B]$ & 17.58 & 17.54 & 25.75 & 25.79 \\
Prob. $i$ wins & 0.5 & 0.5 & 0.5 & 0.5 \\
E[Consumer Surplus] & 2317.9 & 2356.9 & 2862.4 & 2906.9 \\
E[Transfer by $i$ ] & 0 & 0 & 0 & 0 \\
E[Profit for $i$ from $A]$ & 36.42 & 18.43 & 47.53 & 23.98 \\
E[Profit from $B]$ & 633.4 & 629.2 & 1722.3 & 1729.2 \\
E[Welfare] & 3024.2 & 3022.9 & 4679.7 & 4684.0 \\
Relative efficiency & 0.825 & 0.825 & 0.781 & 0.782 \\
\hline
\end{tabular}

Table 5: Expected outcome under a standard auction

\begin{tabular}{|c|c|c|c|c|}
\hline & \multicolumn{2}{|c|}{ Substitutes $\left(d_{2}=-1 / 15 \approx-0.067\right)$} & \multicolumn{2}{|c|}{ Complements $\left(d_{2}=1 / 15 \approx 0.067\right)$} \\
\hline & Private-values & Common-values & Private-values & Common-values \\
\hline $\mathrm{E}[$ Price of $A]$ & 5.74 & 6.00 & 5.59 & 5.50 \\
\hline $\mathrm{E}[$ Price of $B]$ & 17.64 & 17.63 & 25.72 & 25.71 \\
\hline Prob. $N$ wins & 0.56 & 1 & 0.44 & 0 \\
\hline E[Consumer Surplus] & 2307.0 & 2278.99 & 2876.3 & 2889.52 \\
\hline $\mathrm{E}[$ Transfer by $N]$ & 0 & 0 & 0 & 0 \\
\hline $\mathrm{E}[$ Transfer by $E]$ & 0 & 0 & 0 & 0 \\
\hline $\mathrm{E}[$ Profit for $N$ from $A]$ & 44.6 & 746.19 & 36.5 & 0 \\
\hline $\mathrm{E}[$ Profit for $\mathrm{E}$ from $A]$ & 36.0 & 0 & 46.8 & 71.99 \\
\hline $\mathrm{E}[$ Profit from $B]$ & 634.3 & 634.32 & 1723.9 & 1725.69 \\
\hline $\mathrm{E}[$ Welfare $]$ & 3021.9 & 3025.18 & 4683.4 & 4687.20 \\
\hline Relative efficiency & 0.824 & 0.78 & 0.782 & 0.75 \\
\hline
\end{tabular}

\subsection{Sensitivity analysis of the results under private-values ${ }^{14}$}

This section briefly investigates how sensitive the results are to the parameterisation. It will focus on the effect of the cross-price sensitivity $\left(d_{2}\right)$. The effects of other parameters are as one

\footnotetext{
${ }^{14}$ For the common-value, no sensitivity analysis will be presented as nothing interesting happens: the advantaged bidder always wins, and the main effect in the private-values sensitivity analysis is via the advantaged bidder's position.
} 
would expect: for instance, a stronger sensitivity to the own-price decreases market power, and hence private supply fares better and there is less to gain from a price auction.

As discussed and as Figure 3 shows, when the facilities are stronger substitutes (more negative $d_{2}$ ) or stronger complements (more positive $d_{2}$ ), the chance that the new bidder wins a standard auction decreases, as this increases the profit gain from being a monopolist. Indeed, for independent markets, the existing operator is just a regular bidder; for strong substitutes $\left(d_{2}<-0.1\right)$ or complements $\left(d_{2}>0.19\right)$, the existing operator always wins. For substitutes, the relative efficiency increases as $d_{2}$ becomes less negative, as the chance that there will be a duopoly increases. For complements, the relative efficiency also tends to increase with $d_{2}$, because the chance of a duopoly decreases.

Figure 3: Sensitivity of the outcome of the standard auction to the cross-price sensitivity $\left(d_{2}\right)$

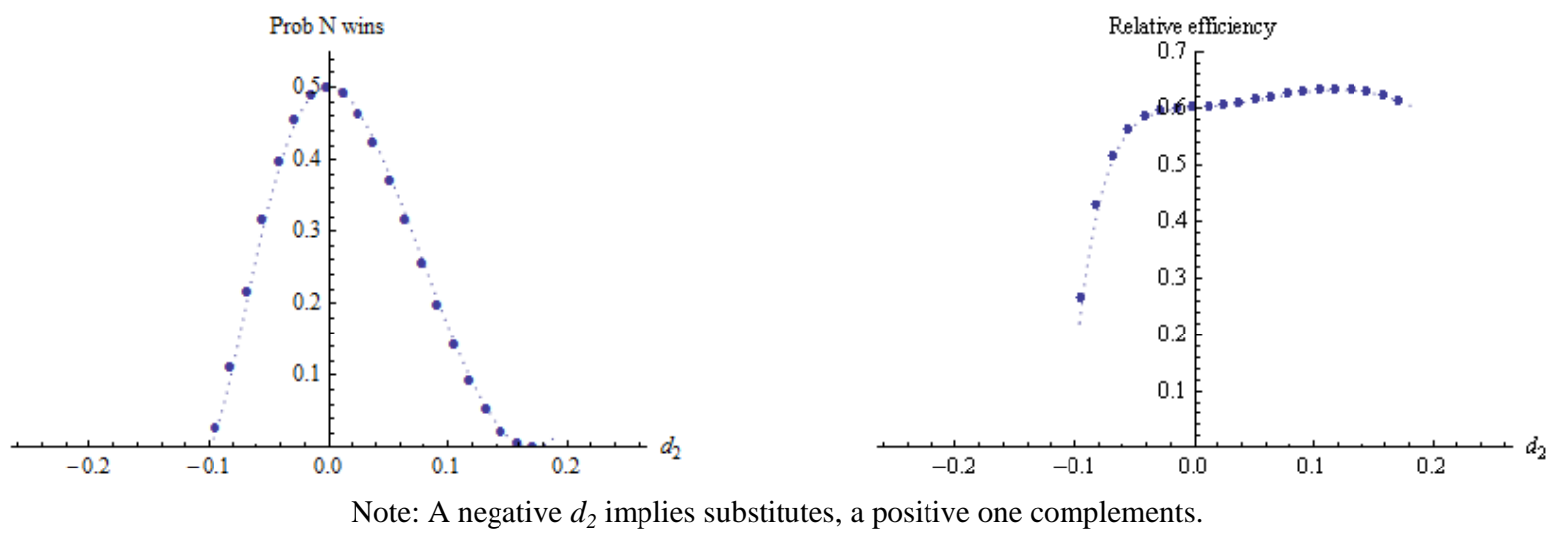

Figure 4 displays the effects of $d_{2}$ in the price auction. With substitutes the new bidder wins more often. This harms the existing operator, but increases welfare by lowering the expected price. With complements, the existing operator wins more often, and this helps welfare by limiting the occurrence of the more harmful duopoly. Moreover, with a maximum price equal to the highest possible marginal cost, there is a much larger region with the price than the standard auction where there is competition in the auction.

Figure 4: Sensitivity of the outcome of the price auction to the cross-price sensitivity (d2)
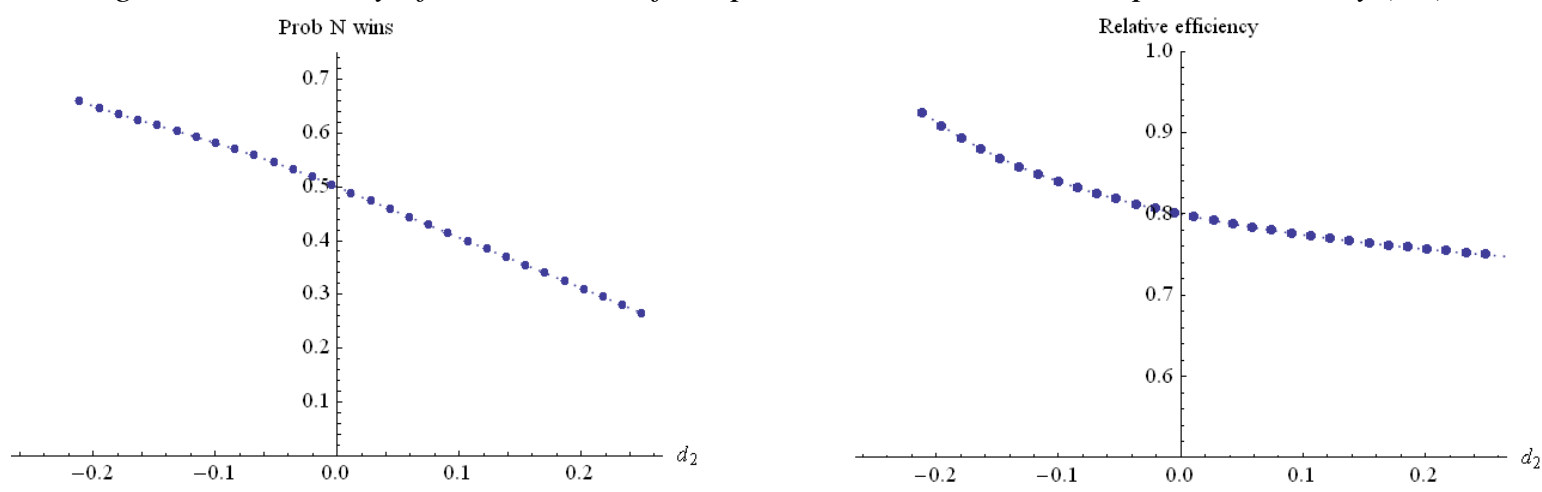

Note: A negative $d_{2}$ implies substitutes, a positive one complements. 


\section{Discussion}

Now we turn to some caveats to the research. The previous sections already discussed that the price auction needs a maximum price, and that it is important what a bidder does when it always loses. The discussion of the welfare effects assumes that the marginal social cost of taxation is zero and thus the value of public funds is one. If the value is higher, the standard auction's revenue is more valuable and thus its welfare higher. With private-values and a standard auction, this could also make the presence of an existing operator bidder welfare improving, as this often increases expected transfer.

Bidders are assumed to differ in (the expectation of) the marginal costs. They could also differ in the intercept of the demand function or the price sensitivity. The results with privatevalues would be qualitatively the same. However, if marginal costs are constant, the priceauction with common-values would be affected: all bidders would then always bid the fixed and shared marginal cost as the price, and thus there would be no advantages. Still, if marginal costs are marginally non-linear, ${ }^{15}$ then there would be a bidder that always wins.

There is also the issue of ex-post incentives to renege or renegotiate the contract, in that the existing operator will make a loss on its new facility if it only just wins the auction. Then, the firm may argue that it cannot be expected to keep its promise. Such tender contract renegotiation is, as Engel et al. (2001) argue, very common.

\section{Conclusion and policy implications}

This paper finds that having an existing operator bidder in a tender auction has substantial effects, and, in many settings, one bidder always wins, and does so at a low payment in the standard auction and a high price in the price auction. However, different from the related cases in the literature, it is not always the existing operator who wins more often. With the price auction and substitute facilities, the new bidder wins more often. With a price auction and complements or a standard auction, the existing operator more often wins. With private values, if the facilities are strong complements or substitutes, the new bidder can never win the standard auction. With common values, the disadvantaged bidder can never win, and the competition in the auction collapses.

All this can have great consequences for the tendering in network markets- A bidder who has little or no chance of winning is unlikely to enter a tender auction. If a firm becomes an existing operator, it may win all future auctions, and at a low transfer or a high (consumer) price. This could severely limit the competition for the field. This is especially true for the "standard auction", whereas the "price auction" often gives smaller advantages, and to new entrants with substitutes which at least makes competition in the field more likely, and to an existing bidder with complements which at least limits the chance of harmful double

\footnotetext{
${ }^{15}$ Or if there are congestion costs (usage costs increase with the number of users) or network effects (the value of consumption for a given user increases with the number of users). Such congestion or network effects would have no effects on the qualiative results in the other settings.
} 
marginalisation. Hence, another advantage of the price is that it is less detrimentally affected by the presence of an existing operator.

A question that remains is: what can the government do to improve the outcome? An option would be a standard auction with price or rate-of-return regulation, such regulation often removes the advantage from being a monopolist and thus the effects of an existing operator. Following McAfee and McMillan (1989), it could help to differentiate between types of bidders to increase the competition in the auction. Following Goeree and Offerman (2004), another alternative to stiffen the auction competition is giving the loser of the auction part of auction revenue. A final option, which has received interest in the takeovers literature, is giving the disadvantaged bidder shares at a discounted price (e.g. Bulow et al., 1998; Rothkopf et al., 2003). Subsidising bidders is also an option in procurement (Cantillon, 2008). In the context of this paper, the government could offer a third facility only to non-existing operators. A further advantage of more and perhaps smaller facilities is that this fosters competition.

\section{References}

Asker, J., Cantillon, E., 2010. Procurement when price and quality matter. RAND Journal of Economics 41(1), 1-34.

Bulow, J., Huang, M., Klemperer, P., 1999. Toeholds and takeovers. Journal of Political Economy 107(3), 427-454.

Burkart, M., 1995. Initial shareholdings and overbidding in takeover contests. Journal of Finance 50(5), 1491-1515.

Cantillon, E., 2008. The effect of bidders' asymmetries on expected revenue in auctions. Games and Economic Behavior 62(1), $1-25$

Che, Y.-K., 1993. Design competition through multidimensional auctions. RAND Journal of Economics 24(4), 668-680.

Chen, Y, 2000. Strategic bidding by potential competitors: will monopoly persist? The Journal of Industrial Economics 48(2), $161-175$.

Cramton, P., Gibbons, R., Klemperer, P., 1987. Dissolving a partnership efficiently. Econometrica 55(3), 615-32.

De Silva, D.G., Dunne, T., Kosmopoulou, G., 2003. An empirical analysis of entrant and incumbent bidding in road construction auctions. The Journal of Industrial Economics 51(3), 295-316.

Economides, N., Salop, S.C., 1992. Competition and integration among complements, and network market structure. Journal of Industrial Economics 40(1), 105-123.

Engelbrecht-Wiggans, R., 1994. Auctions with price-proportional benefits to bidders. Games and Economic Behavior 6(3), 339-46.

Flyvbjerg, B., Holm, M.K.S., Buhl, S.L., 2003. How common and how large are cost overruns in transport infrastructure projects? Transport Reviews 23(1), 71-88.

Flyvbjerg, B., Holm, M.K.S., Buhl, S.L., 2006. Inaccuracy in traffic forecasts. Transport Reviews 26(1), 1-24.

Gal-Or, E., 1985. First mover and second mover advantages. International Economic Review 26(3), 649-653.

Gilbert, R., Newbery, D., 1982, Preemptive Patenting and the Persistence of Monopoly'. American Economic Review 72(3), 514-526.

Goeree, J.K., Maasland, E., Onderstal, S., Turner, J.L., 2005. How (not) to raise money. Journal of Political Economy 113(4), 897-918.

Goeree, J.K., Offerman, T., 2004. Notes and comments the Amsterdam auction. Econometrica 72(1), 281-294.

Hazlett, T.W, Muñoz, R.E., 2009. A welfare analysis of spectrum allocation policies. RAND Journal of Economics 40(3), 424454.

Klemperer, P., 1998. Auctions with almost common values: the 'wallet game' and its applications. European Economic Review 42(3-5), 757-769.

Krishna, V., 2010. Auction Theory, 2nd edition. Amsterdam: Academic press.

Krishna, V., Rosenthal, R., 1996. Simultaneous auctions with synergies. Games and Economic Behavior 17(1), 1-31.

Laffont, J.J., Tirole, J., 1993. A Theory of Incentives in Procurement and Regulation. Cambridge: MIT Press.

McAfee, P.R., McMillan, J., 1989. Government procurement and international trade. Journal of International Economics 26(3-4) 291-308.

Mougeot, M., Naegelen, F., Designing a market structure when firms compete for the rigth to serve the market.Journal of Industrial Economics, 53(3), 393-416.

Mouwen, A., Rietveld, P., 2012. Does competitive tendering improve customer satisfaction with public transport? A case study for the Netherlands. Transportation Research Part A 51, 29-45.

Rothkopf, M.H., Harstad, R.M., Fu , Y., 2003. Is subsidizing inefficient bidders actually costly? Management Science 49(1), 71-84.

Singh, R., 1998. Takeover bidding with toeholds: the case of the owner's curse. The Review of Financial Studies 11(4), 679704.

Verhoef, E.T., 2007. Second-best road pricing through highway franchising. Journal of Urban Economics 62(2), $337-361$. 